\title{
An Empirical Evaluation of the Link between Women Participation in Village Savings and Loans Association (VSLA) and Poverty Reduction in Ethiopia
}

\author{
Nardos Legesse Beyene ${ }^{1, *}$ and Mulugeta F. Dinbabo ${ }^{2}$ \\ ${ }^{1}$ Independent Development Economics Researcher, University of the Western Cape, Faculty of Economics \\ and Management Science at the University of the Western Cape, South Africa \\ ${ }^{2}$ Institute for Social Development, Faculty of Economics and Management Science at the University of the \\ Western Cape, South Africa
}

\begin{abstract}
Women's participation is a fundamental prerequisite for gender equality and genuine democracy. It facilitates women's direct engagement in decision-making and is a means of ensuring better accountability to women. This paper assesses the impact of women participation in Village Savings and Loans Association (VSLA) on poverty reduction in Hawassa city, Ethiopia. Using a mixed research methodology, and applying propensity score matching, the study found that women participation in VSLA has a significant positive impact in increasing average monthly household income of participant woman. Besides, women participation in VSLA has a significant positive association with improvements in household diet, health, children's education, and women's involvement in household decisions. The study recommends a reinforcement of government and nongovernmental organizations in providing regular and need based capacity building trainings for VSLA participants followed by a concerted effort to link VSLA participants with formal microfinance institutions.
\end{abstract}

Keywords: Capacity building, decision-making, Ethiopia, loans, participation, poverty, village savings and women.

\section{INTRODUCTION}

Poverty is a pervasive problem in our society. Spanning across the world, poverty exists in different levels and various forms. As the World Bank broadly defines it, poverty is a "pronounced deprivation in wellbeing," (Haughton \& Khandker, 2009: 2). Due to the profound impact that poverty has on the poor's well-being, efforts have been made by various governments, international governmental and nongovernmental organizations to combat extreme poverty. As a result of coordinated efforts, since 1985 extreme poverty has been reduced in every region of the globe. This reduction has been the result of many factors and developmental policies implemented over the past 30 years. Among many factors, the most unique developmental programme pioneered by Mohammed Yunus is prominent. This programme is called Microfinance. Microfinance often provide micro loans to poor people and low income clients without collateral and used to start and expand small businesses which ultimately aimed to help the poor break the vicious cycle of poverty (Yunus, 1999: 149).

The primary objective of Microfinance Institutes (MFIs) is to create a small and easily accessible loan to

*Address correspondence to this author at the Independent Development Economics Researcher, University of the Western Cape, Faculty of Economics and Management Science at the University of the Western Cape, South Africa; Tel: +251 932512383; E-mail: Inardos@yahoo.com the poor that can foster pro-poor growth. Researchers (Brannen, 2010; Dunn \& Arbunkle, 2001; Kabeer, 1997; Fredrik, 2013; Mochoge, 2016) argue that microfinance can facilitate poverty reduction through improved quality of life on the one hand and women's economic empowerment on the other. Moreover, microfinance interventions may lead to empowerment of women by increasing their incomes and their control over that income, enhancing their knowledge and skills in production and trade, and increasing their participation in household decision-making (Kabeer, 1997; Fredrik, 2013). As a result, social attitudes and perceptions may change, and women's status in the household and community may be enhanced. Though many banks and microfinance institutions (MFIs) provide valuable services to the poor in the developing world, they are most successful in economically dynamic urban areas, where investment opportunities abound; the borrowing requirements of small-scale enterprises are high; income streams are regular and diverse and the cost of reaching clients is low. Thirty years since the start of the microfinance revolution, people who live in many rural areas and urban slums, and those who are very poor, have a difficult time gaining access to useful microfinance products (Brannen, 2010). Yunus also stated that "formal institutions such as commercial banks pronounced a death sentence on the poor because they rejected the poor as unworthy of credit, imposing a financial apartheid." (Yunus, 1999, p.149). In relation to this, 
most women, in developing countries, are not willing to approach credit institution since the collateral the finance institutions requested from poor women is more than they can afford (Bekele \& Jacobs, 2008). In addition, the World Bank (2007) observed that from the 193.6 million families which are categorized as poor worldwide, only $47.8 \%$ were found to be in the range of reaching the formal financial institutions' services (Mochoge, 2016, p. 1).

The situations, as stated above, initiated for the evolution of village saving and loan as a significant model for creating access to financial resource to destitute poor in urban slums and rural areas. Village Savings and Loans (VSL) is a concept developed by CARE International, an international NGO, and implemented by Moira Eknes in CARE's Matu Masa Dubara (Women on the Move) project in Niger in 1991(Hugh, 2002: 1). The Village savings and loans (VSL) model is a self-managed and self-capitalized microfinance methodology. By having its members mobilize and intermediate local pools of investment finance, it offers savings, insurance and credit services in markets outside the reach of formal institutions (Edengenet, 2016).

In the context of Ethiopia, the legislation in microfinance was enacted in 1996. Accordingly, women in both urban and rural areas of Ethiopia are accessing microcredit and benefiting from services of various MFIs (Bekele \& Jacobs, 2008; Bekele \& Worku, 2008). However, the participation of women in the MFIs are not at the desired level due to various factors including but not limited to the awareness and literacy level of women regarding the credit and repayments and the inability of women to provide collateral. Athough the amount is too small and limited to petty trading, and informal sector activities, Bamlaku, (2006) argues that it is much more convenient to them in terms of ease of access, and the fact that they dealt with people from close community (Bamlaku, 2006). This empirical research aimed to assess the impact of village savings and loan associations in poverty reduction at household level, in Hawassa city.

\section{LITERATURE REVIEW/THEORETICAL FRAME- WORK}

A great deal of literature is available on the effects of microcredit and community managed saving and loan associations on poverty reduction, community and local development, both in developed and developing countries. These include (Allen \& Hobane, 2004;
Anyango, 2005; Dinbabo, 2005; Dinbabo, 2012; Dinbabo, 2013; Dinbabo, 2014; Dunn \& Arbunkle, 2001; Hossaena, 2013; Khandker, 2005; Morduch, 1998; Mutesasira \& Mule, 2003; Terry, 2006; Wosene, 2014, Sherin, 2012).

Reviewing the literature investigating the microcredit impact on poverty alleviation shows disparities between supporters and opponents. On one side of the argument there are significant positive effects for microcredit programs on household material and social well-being with further spill-over effects on the local economy while on the other side of the argument, there are well documented negative effects, particularly on the extreme poor (Sherin, 2012). Several studies ( Hossaena, 2013; Terry, 2006; Khandker, 2005; Dunn \& Arbunkle, 2001) have found that access to microfinance services decreases the incidence of poverty. According to this group of researchers, microcredit programs have a positive impact not merely on the poor household income and consumption level but on their social wellbeing as well, reflected by the impact of these programs on recipients' level of education, health and children nutrition. Furthermore, it extends to women's feelings of empowerment and independence.

Dunn and Arbunkle (2001) found that only 28 percent of microfinance clients in Lima, Peru live below the poverty line compared to 41 percent of non-clients. Khandker (2005) also found positive effects on poverty rates in Bangladesh. He found that between 1991/92 and $1998 / 99$, moderate poverty in all villages declined by 17 percentage points: 18 points in areas where Grameen Bank or BRAC was active, and 13 points in non-program areas. Microfinance thus helps not only poor participants but also the local economy. Overall, Khandker (2005) found that microfinance accounts for 40 percent of the entire reduction of moderate poverty in rural Bangladesh.

Terry (2006) finds that loans from FINCA-Tanzania create major positive changes in the lives of female borrowers, including an improvement in social status and self-esteem, and an increase in confidence. Women also feel empowered through an increase in income and the ability to accumulate savings, purchase household assets and contribute towards their children's education. The findings also suggest that members of the household and the community, at large, view female participants in a more positive way. However, Terry relies completely on qualitative data and does not include a control group. Therefore, the 
results of the study are not necessarily reliable. On the other side of the argument, Morduch (1998) in his study in Bangladesh found no evidence indicating higher consumption levels or educational enrolments for children of loan holders, but merely a reduction in consumption variability across the seasons for the participants. He has used a cross sectional survey of 180 respondents from participants and non-participants in microcredit programmes. Accordingly, microcredit programmes were not found to enable households to increase their consumption level but simply offered them "ways to smooth their consumption through smoothing income". He mentioned that this benefit is negligible compared to the program costs.

There are also numerous studies on the village savings and loan associations, which are exclusively categorized under the community saving and credit groups, which collect members saving to provide loan and small insurance services to its members. Recent empirical evidence suggests that well developed VSL schemes can help individuals to improve incomes, broaden investment opportunities; thus, reduce poverty as well lower income inequality between women and men (Wosene, 2014). Allen and Hobane (2004) concluded that the VSLA have contributed to increased household productive and non-productive asset levels. The study further noted that there has been a significant reduction in the use of formal-sector and traditional savings instruments. The number of incomegenerating activities per household increased and income generating activities (IGA) became more stable, while household labour allocated to IGAs increased. Eighty-one percent of respondents felt that their status in the community had improved due to their association with their VSLAs. Anyango (2005) reached similar conclusions. The findings showed that the VSLA program had helped to improve the livelihoods of its members and alleviate poverty, particularly for women who constitute the majority in the VSLA groups. The number of economic activities that members of VSLA were engaged in at the baseline had increased, as had the magnitude of other activities. Mutesasira and Mule (2003) in their study in Uganda concluded that most VSLAs were comprised of very low-income people. The average savings per member and the average loan size provided some evidence of the depth of outreach.

Wosene (2014) in her study on poor women and their social capital, which is an exploratory study of the village saving and loan groups' (VSLGs) contribution to women's empowerment in Ethiopia, West Harergie, she found that VSLG contribute positively on the social capital, children schooling, enhance the decision making power of women, economic empowerment of poor women, harmony within the family, improvement of saving culture, ensures security, change in social status, increase in social interaction, enhanced selfconfidence and hope of a better future.

Dinbabo, (2005; 2012; 2013; 2014) also undertook an evaluation study on community development and poverty reduction using a case study area in the Southern Region of Ethiopia. His methodology employed both quantitative and qualitative approaches. Dinbabo, (2014) argues that participatory development can significantly enhance the effectiveness of any microfinance activities in terms poverty reduction at the community level. Respondents who participated in the study found that it went far in supporting their work and in creating awareness among a range of stakeholders about the needs of the intended beneficiaries (i.e., the poor). Furthermore, they believed that the costs of participation were small as compared with the gains. Dinbabo $(2012 ; 2014)$ further argues that stakeholders participation strengthens the effectiveness of microfinance and sustainability of any kinds of poverty reduction at the community level.

\section{METHODOLOGY}

The research employed a mixed research methodology, which involved both quantitative and qualitative approaches. Under qualitative, the research collected data by applying focus group discussion with VSL members. Yamane (1967:886) sample size determination formula was applied; assuming $p=0.5$ (maximum variability), the researchers desire a $95 \%$ confidence level and $\pm 5 \%$ precision level and a total of 254 samples were identified. The study applied propensity score matching (PSM) and comparative analysis (using Pearson's Chi-square test and independent t-test) through 'with' and 'without' and using treatment group ${ }^{1}$ being old VSLA women members (labeled as participants) of 127 in total and comparison groups ${ }^{2}-127$ new VSLA women members (labeled as non-participants) scenario. The propensity score matching is used to assess the impact of village

${ }^{1}$ The treatment groups are those VSLA members who are in operation for three months and more. These group have started mobilizing savings and disbursing loan. For ease of use, the study labels the treatment groups as - participants.

${ }^{2}$ The comparison groups used in the study are those VSLAs in early stage of their formation (less than 3 months). These groups are in the stage of setting up association constitution, taking some initial trainings from village agents, and on process of saving but have not yet started disbursing loan to the members. Throughout the study, the comparison groups are labeled as nonparticipants. 
saving and loan (VSL), while the comparative analysis is done with the aim of assessing the similarities and differences between the old (participants) and new (non-participants) VSLA members in terms of various individual and household poverty indicators including women participation in community works, decision making in household, household members health status, children education, and household diet.

The analysis is used by assuming the two groups (old members - as participants and new members in VSLA as non-participants) and their household have common characteristics and poverty profile with the only difference being the disbursement of loan in old VSLA women members, which is used by the loan takers for income generation purpose. As such, the comparison analysis helps to understand the effects of women participation in village saving and loan and the subsequent income generating activities on individual, and household poverty reduction, that lead to urban poverty reduction.

\section{Model Specification: Propensity Score Matching}

The analysis in this study relies on the use of propensity score matching (PSM) primarily due to the nature of the program and data available, and the recognition that PSM is an influential approach to estimating impact in a straightforward manner (Dillon 2011). Although the 'gold standard' in evaluating impact is implementing randomized control trials (RCTs), this technique is not viable in this setting due to program placement/targeting (Dercon et al. 2009) and self-selection. The alternative approaches to dealing with attribution of impact to interventions and determining the counterfactual outcome of participants are quasi-experimental techniques, one among them is the PSM (Caliendo and Kopeinig 2008).

Propensity-score matching (PSM) is a quasiexperimental option used to estimate the difference in outcomes between beneficiaries and non-beneficiaries that is attributable to a particular program. The basic idea of PSM is to match program participants (old village saving and loan women participants) with nonparticipants (new village saving and loan women participants). But matching in terms of covariates, the exogenous variables, is very difficult since it is hard to find women which are exactly the same but different only on receiving of loan (Khandker, et al. 2010). To solve this problem the matching process is done in the probability of participating in the program on the basis of observable characteristics (Khandker, et al. 2010). It means PSM constructs a statistical comparison group of VSL women participation and VSL women nonparticipation based on the propensity score of VSL women participation. Thus, the following paragraphs presented the propensity score matching, its model and Average Treatment Effect on the Treated (ATT) Estimation techniques.

The first step in propensity score estimation (PSE) technique is estimation of propensity score. According to Rosenbaum and Rubin (1983), matching can be performed conditioning only on $\mathrm{P}(\mathrm{X})$ rather than on $\mathrm{X}$, where $P(X)=$ Prob $(D=1 \mid X)$ is the probability of participating in the program conditional on $X, X$ being a set of observable characteristics. The same authors explained that, if outcomes without the intervention are independent of participation given $\mathrm{X}$, then they are also independent of participation given $P(X)$ which reduces a multidimensional matching problem to a single dimensional problem.

To obtain the estimated propensity score, we have to choose the model for the estimation and variables that should be incorporated in the model. The models which commonly used to estimate the probability of participation against non-participation households are logit and probit models. Moreover, the two models provide the same result (Gujarati, 2004, pp. 595-596). According to Caliendo and Kopeinig (2005), Logit model is easier to compute than that of probit model and it is widely used. Hence, due this merit in this study the logit model was used for estimating the propensity scores.

In estimating the logit model, the dependent variable is participation which takes a value of 1 if the household participated in a program and 0 otherwise (Gujarati, 2004, pp. 595-596). Thus, mathematically the logit model is formulated as follows:

$P i=E(Y=1 \mid X i)=\beta 0+\beta 2 X i$

Where $X$ is the target outcome and $Y=1$ means a woman participates in VSLA

Now reconsider equation (1) as

$P i=E(Y=1 \mid X i)=\frac{1}{1+e^{-(\beta 0+\beta 2 X i)}}$

For ease of exposition, we write equation (2) as

$P i=\frac{1}{1+e^{-z i}}=\frac{e^{z}}{1+e^{z}}$ 
Where,

$\mathrm{Pi}$ is the probability of woman participating in VSLA

Zi represents cumulative logistic distribution function

$Z i=\beta 0+\sum \beta i X i+U i$

Where,

$i=1,2,3, \ldots, n$

$\beta 0=$ intercept

$\beta i=$ regression coefficients to be estimated

Ui = a disturbance term, and

$\mathrm{Xi}=$ pre-intervention woman and their household characteristics

If $\mathrm{Pi}$, the probability of woman participating in VSLA, is given by equation $(3)$, then $(1-\mathrm{Pi})$, the probability of woman not participating in VSLA, is;

$1-P i=\frac{1}{1+e^{Z i}}$

Then the odds ratio can be written as:

$\frac{P i}{1-P i}=\frac{1+e^{Z i}}{1+e^{-Z i}}$

The left-hand side of equation (6), (Pi/1-Pi) is simply the odds ratio in favors of participating in VSLA. It is the ratio of the probability that the household would participate in the VSLA to the probability that he/she would not participate in the VSLA. Lastly, by taking the natural log of equation (6) the log of odds ratio can be written as:

$L i=\ln \left[\frac{P i}{1-P i}\right]=z i=\beta 0+\sum_{i=1}^{n} \beta i X j i+\varepsilon i$

Where, $L i$ is log of the odds ratio in favor of participation in the VSLA, which is not only linear in $\mathrm{Xji}$ but also linear in the parameters, and $\beta 0$ is the propensity score of the observable individual and household characteristics.

Propensity Score Matching estimation generated through the logit model should include predictor variables that influence the selection procedure or program participation and the outcome of interest (Rosenbaum and Robin, 1983; Bryson et al., 2002).

\section{Matching Estimators/Algorithm}

The next step after the estimation of propensity score is choosing between different matching estimators. There are various matching estimators of PSM are available ${ }^{3}$. Below, only the most commonly applied matching estimators were described for this study.

\section{Average Treatment Effect on the Treated (ATT) Estimation}

ATT Estimation is the last steps of the PSM estimation procedure. Its empirical specification is explained as Caliendo and Kopeinig (2005). In this case estimating the effect of women's participation in the VSLA saving and loan on a given outcome $(Y)$ is specified as

$T i=Y i(D i=1)-Y i(D i=0)$

Where $T i$ is treatment effect (effect due to participation in VSLA), Yi is the outcome on women's household $i, \mathrm{Di}$ is whether woman $i$ has got the treatment or not (i.e., whether woman participated in the VSLA saving and loan or not).

On the other hand, it is understood $Y i(D i=1)$ and $Y i$ $(D i=0)$ cannot be observed for the same woman household at the same time. Moreover, estimating individual treatment effect $T i$ is impossible and one has to shift to estimate the average treatment effects of the population rather than the individual one. As described in Caliendo and Kopeinig (2005, p.3) and Becker and Ichino (2002), the most commonly used average treatment effect estimation is an average Treatment Effect on the Treated (ATT) which is specified as:

$T_{A T I}=E(T \mid D=1)=E[Y(1) \mid D=1]-E[Y(0) \mid D=1]$

This helps to know; how much the woman and their respective households are benefited due to woman's participation in the VSLA saving and loan as compared to those do not participated (Caliendo and Kopeinig 2005, p.3). As the counterfactual mean for those being treated, $E[Y(0) \mid D=1]$ is not observed, one has to choose a proper substitute for it in order to estimate ATT. One may think to use the mean outcome of the untreated individuals, $E[Y(0) \mid D=0]$ as a substitute to

${ }^{3}$ all estimators described here provide consistent estimates of the average treatment on treated ATT under the Conditional Independence Assumption $(\mathrm{CIA})$ and the overlap condition (see further) (for details Caliendo and Kopeinig, 2005). 
the counterfactual mean for those being treated, $E[Y(0) \mid D=1]$. However, this is not a good idea especially in non-experimental studies because it is likely that components which determine the treatment decision also determine the outcome variable of interest.

In this particular case, for instance, variables that determine women's participation in the VSLA could also affect our outcome of interest (e.g. average monthly household income). Hence, the outcomes of individuals from treatment and control group would differ even in the absence of treatment leading to a self-selection bias.

By rearranging and subtracting $E[Y(0) \mid D=0]$ from both sides of equation 9 , ATT can be specified as:

$$
\begin{aligned}
& E[Y(1) \mid D=1]-E[Y(0) \mid D=0]= \\
& T_{A T I}+E[Y(0) \mid D=1]-E[Y(0) \mid D=0]
\end{aligned}
$$

From the above equation 10, both terms in the left hand side are observables and ATT can be identified, if and only if $E[Y(0) D=1]-E[Y(0) D=0]=0$. i.e. when there is no self-selection bias. This condition can be ensured only in a randomized experiment (i.e., when there is no self-selection bias). Thus, in nonexperimental studies like PSM, statistical techniques is used to construct artificial control group. More specifically we match every possible treatment with non-treatment observation with most similar (observable) characteristics (Gertler et al., 2011).

\section{Hypothesis Testing}

Pearson's Chi-square test is also used to examine if there is a statistical significant association between two categorical variables. In the context of this study, Pearson's Chi-square test is used to assess whether there is statistically significant association between health status of VSLA members households (1household members health improved or 0 - otherwise /remain the same, worsened or I do not know/) and VSLA membership status (new as participants or old members as non-participants); children education status (1- children education improved or 0 - otherwise /remain the same, worsened or I do not know/) and VSLA membership status (new or old members); household diet : quality and quantity of food consumed by household members (1- household diet improved or 0 - otherwise) and VSLA membership status (new or old members); women participation in community activities (1 - improved or 0 otherwise) and VSLA membership status (new or old members).
As the samples are randomly derived, and the group variables (VSLA status - new and old) and the test variables (household members' health status, children education, household diet, and women participation in community activities) are nominally scaled, Pearson's chi square test is the appropriate statistical tool for testing the hypotheses. The decision rule is that, if the significance value is higher than the significance level ( 0.05 in this study), then the null hypothesis has to be accepted, meaning that the analyzed variables are independent from each other, in other words, the difference between the groups is not significant. On the contrary, if the significance value is less than or equal to the significance level $(0.05)$, then the null hypothesis must be rejected, meaning that the analyzed variables are dependent on each other, and in other words, the difference between the two groups is significant. Beside these, independent t-test is applied to check whether there is statistically significant difference or not for metric test variable, and group variable that is nominal. Same decision rule is applied to decide on the significance.

In addition to the quantitative data analysis applying propensity score matching and hypothesis testing, qualitative data that is generated from focus group discussion is organized in meaningful way, analyzed qualitatively by transcribing and categorizing, and presented in narrative way.

\section{RESULTS AND DISCUSSION}

In this study, through reviewing both theoretical and empirical sources and other studies conducted using propensity score matching dealing with microfinance and poverty, the study included a number of variables in the model to estimate the propensity score. Hence, the next section deals with the descriptive statistics of these covariates.

\section{Descriptive Statistics of Covariates}

Reveals that there exists a statistically significant difference between treatment and comparison respondents regarding age, marital status, education, household size, work experiences prior to village saving and loan, number of people earning income in household and number of financially dependent people in household.

In addition to the descriptive statistics of covariates, results of the logistic regression, as shown in Table 2 below, also indicate that age of woman, work 
Table 1: Descriptive Statistics of Covariates

\begin{tabular}{|c|c|c|c|c|}
\hline \multirow[b]{2}{*}{ Variable description } & \multirow[b]{2}{*}{ Overall } & \multicolumn{2}{|c|}{ VSL status } & \multirow[b]{2}{*}{ t-test/Chi-sq. test } \\
\hline & & $\begin{array}{c}\text { Treatment } \\
\text { (Old VSLA members/ } \\
\text { participants) }\end{array}$ & $\begin{array}{c}\text { Comparison } \\
\text { (New VSLA/ } \\
\text { non-participants) }\end{array}$ & \\
\hline Number of observations & 254 & 127 & 127 & \\
\hline Age of woman & 42.83 & 44.64 & 41.02 & $-4.9835^{\star * *}$ \\
\hline $\begin{array}{c}\text { Married woman ( } 1 \text { if woman is } \\
\text { married) \% }\end{array}$ & 50.0 & 59.84 & 40.16 & $9.8425^{\star * *}$ \\
\hline $\begin{array}{c}\text { Education (1 if woman attended } \\
\text { school) \% }\end{array}$ & 41.73 & 56.60 & 43.40 & $3.1734^{*}$ \\
\hline Household size & 3.48 & 3.94 & 3.03 & $-4.6402^{\star * \star}$ \\
\hline $\begin{array}{l}\text { Woman work status prior VSLA ( } 1 \text { if } \\
\text { woman worked) \% }\end{array}$ & 88.6 & 81.9 & 95.3 & $11.25^{* * *}$ \\
\hline $\begin{array}{c}\mathrm{HH} \text { head (1 if female headed the } \\
\mathrm{HH} \text { ) }\end{array}$ & 44.9 & 40.94 & 49.61 & 1.9227 \\
\hline $\begin{array}{c}\text { Number of people earning income } \\
\text { in } \mathrm{HH}\end{array}$ & 1.61 & 1.77 & 1.45 & $-4.7539^{* * *}$ \\
\hline Number of dependents in $\mathrm{HH}$ & 2.61 & 3.01 & 2.20 & $-5.2279^{* * *}$ \\
\hline
\end{tabular}

Source: Author calculation and estimation based on survey data.

Note: Test of statistical significance of mean differences between treatment and control/comparison households: ${ }^{* *} p<0.01,{ }^{* *} p<0.05,{ }^{*} p<0.1$.

Table 2: Propensity Score Estimation Using Logit Model

\begin{tabular}{|c|c|}
\hline Variable & Regression Coefficients \\
\hline \hline Constant & $-5.270048^{* * *}(1.405599)$ \\
\hline Age of woman & $0.910^{* * *}(0.268)$ \\
\hline Married woman (1 if woman is married) $\%$ & $0.010(0.207)$ \\
\hline Education (1 if woman attended school) $\%$ & $0.216(0.213)$ \\
\hline Household size & $-0.269(0.200)$ \\
\hline Woman work status prior VSLA (1 if woman worked) $\%$ & $-1.484^{* * *}(0.464)$ \\
\hline HH head (1 if female headed the HH) & $0.431(0.502)$ \\
\hline Number of people earning income in HH & $1.254^{* * *}(0.456)$ \\
\hline Number of dependents in HH & $0.420^{* *}(0.211)$ \\
\hline No. of Observations & 254 \\
\hline Wald Chi-Square & 42.64 \\
\hline Pseudo R-squared & 0.1586 \\
\hline
\end{tabular}

Source: Author calculation and estimation based on survey data.

Note: Dependent variable: Woman participation in village savings and loans associations for more than 3 months, with saving and loans $=1$ or not $(=0)$; Standard errors in parenthesis. Statistical significance based on Z statistics. Significance at ${ }^{* * *} p<0.01,{ }^{* *} p<0.05,{ }^{*} p<0.1$.

experience prior to VSL, number of people earning income in household, and number of financially dependents in household are significant predictors of participation in village saving and loan.

As shown in Table 2, in terms of age of woman, it seems that older woman has better chance of participating in village saving and loan compared to the young one. This could be because of the economic pressure that women face at higher ages and most look for alternative means of saving and loan to start income generating activities. Working experience of women prior to joining village saving and loan is negatively related to participation probably because working women might find other alternative means of saving other than village saving and loan. These women might also be able to take small loans from formal microfinance institutions by using some 
Table 3: Estimation of Average Effect of Participation in VSL on Average Monthly Household Income Using Nearest Neighbor and Kernel Matching

\begin{tabular}{|c|c|c|}
\hline Outcome Variable & $\begin{array}{c}\text { ATT estimates using nearest-neighbor } \\
\text { estimator }\end{array}$ & $\begin{array}{c}\text { ATT estimates using Kernel } \\
\text { matching estimator }\end{array}$ \\
\hline \hline Average monthly household income & $169.63^{* *}(66.517)$ & $141.55^{* *}(86.029)$ \\
\hline No. of observations & 254 & 249 \\
\hline Treated & $127^{4}$ & 127 \\
\hline Comparison & 127 & 122 \\
\hline
\end{tabular}

Source: Own calculation and estimation based on survey data

collateral from their work. Number of people earning income positively affects participation. Finally, number of dependents in household positively affects participation, which may be because as the number of dependents increases in household, there will be increased demands from the dependents which could force woman to partake in village saving and loan and start income generating activities using loans.

\section{Women Participation in Village Saving}

The participation of women in all aspects of society are more important specially, in decision-making structures which ensures the possibilities for entrenching the principles of democracy in a society (Dinbabo, 2014). In order to assess women participation in village saving, estimation of the average effect of women participation in village saving and loan on outcome variable, average monthly household income, (ATT) was performed. The results as presented in Table 3 indicated that the average effect of participation in village saving and loan on average monthly household income of participant women is positive and significant at $5 \%$ significance level. The ATT results shows women participating in VSLA for three and more months accessing both savings and loans attributed higher average monthly household income ranging from 169.63 Birr/month (nearest neighbor matching) to 141.55 Birr/month (Kernel matching), on average as compared to non-participants (those women who are in less than three months and have not yet accessed VSLA loan).

As shown in Table 3, there is convergence of results obtained using "Nearest neighbor" and "Kernel matching." This implies that the results are robust. Hence, assuming there is no selection bias due to

\footnotetext{
${ }^{4}$ Note: 127 treated and 122 comparison individuals on common support. Standard errors in parenthesis.

**indicate statistical significance at the $5 \%$ levels.
}

unobservable factors, women participation in village saving and loan has a positive and significant effect on average monthly household income.

With respect to the matching quality and common support condition, similar to Wordofa and Sassi (2017) as well as Arpino and Aassve (2005), the study implemented mean comparison (before and after matching), standardized bias, and overall measures of covariates imbalance to check matching quality. The mean comparisons between the two groups before matching indicate the existence of significant differences for most of the variables. However, the post-matching t-test results indicate that most of these variables are adjusted and shows non-significant differences, implying that the matching procedures enabled balancing the covariates. The variables age of woman, household size, number of people earning income in household, and number of dependents in household show high standardized percentage bias in the unmatched sample and the post matching results show a significant reduction in the percentage bias for most of the covariates making it below $30 \%$. In addition to these, the overall measure of covariate balance as, shows the mean bias of $41.6 \%$ in the unmatched sample is reduced to $20.3 \%$ in the matched one. The pseudo R-square, which is 0.159 in the unmatched sample is reduced to 0.048 implying that the matching procedure is effective in reducing existing biases.

\section{Comparative Analysis via Hypothesis Testing}

\section{Household Diet}

In this paper, both women participants in VSL (treatment group) and non-participant women (comparison group) respondents were asked their perception regarding the household diet in terms of the variety, quantity and quality of food consumed by household members. The study assumed participants with access to loan from their village saving and loan associations will be able to partake in income 
Table 4: Chi-Square Test for Perception Towards their Household Diet

\begin{tabular}{|c|c|c|c|}
\hline \multirow{2}{*}{ Perception on household diet } & \multicolumn{2}{|c|}{ VSL status } \\
\cline { 2 - 4 } & Participants & 42 & Non-participants \\
\hline \hline \multirow{2}{*}{ Improved } & 113 & 77.5 & 155 \\
\cline { 2 - 4 } & 77.5 (Exp. Freq.) & 85 & 99 \\
\hline \multirow{2}{*}{ Otherwise (stayed same, I don't know) } & 14 & 49.5 & 127 \\
\cline { 2 - 4 } & 49.5 & 127.0 & 254 \\
\cline { 2 - 4 }
\end{tabular}

Source: Author calculation and estimation based on survey data

Exp. Frequency: expected frequency Note: Pearson chi2(1) $=83.4418 \operatorname{Pr}=0.000$.

generating activities through which they will be able to afford to purchase a better quality and quantity of food for their household as compared with non-participants. Thus, women VSL participants and their households are expected to have improved consumption of variety foods and face few challenges in satisfying the food needs of their family than non-participants.

The results in Table 4 shows Pearson's chi-square value of 83.4418 at 1 degree of freedom and a significant value at 0.000 . According to the decision rule, the significant value $(0.000)$ is less than the level of significance $(0.05)$ used in the study. Therefore, we reject the null hypothesis in favor of the alternative hypothesis. This means that there is an association between improvement on household diet and women participation in village saving and loan, and the difference between the participant and non-participant women and their households are significant. This finding is in line with evidence from Bondo District, Kenya study by Hongo A. (2013: 92) which suggest that majority of women participating in village savings and loan association attributes their ability to ensure food quality at the households to their participation in the associations.
Focus group participants were also asked to discuss and reflect their views regarding their household diet by comparing before and after scenario. The various views reflected from participants during discussion shows that an improved diet have been achieved by women's households after their participation in VSLA. One of the focus group discussion participants has explained the household diet improvement as;

"Prior to joining VSL, I and my families were hardly able to eat 2 times a day. I tried everything to offer my children the quantities and qualities of food I can afford. Despite all my efforts, the food was not satisfactory to my family. However, now I am working in income generating activities and earn money. As a result, we afford a meal three times a day. We are eating foods comprising vegetables and rarely meat, which I think is balanced and the quantity of food is fair enough for my family." (FGD,2017)

Table 5: Chi-Square Test - Respondents' Perception Towards their Household Health

\begin{tabular}{|c|c|c|c|}
\hline \multirow{2}{*}{ Perception on household diet } & \multicolumn{2}{|c|}{ VSL status } & \multirow{2}{*}{ Total } \\
\hline & Participants & Non-participants & \\
\hline \multirow{2}{*}{ Improved } & 116 & 53 & 169 \\
\hline & 84.5 (Exp. Frq.) & 84.5 & 169 \\
\hline \multirow{2}{*}{ Otherwise (stayed same, I don't know) } & 11 & 74 & 85 \\
\hline & 42.5 & 42.5 & 85.0 \\
\hline \multirow{2}{*}{ Total } & 127 & 127 & 254 \\
\hline & 127.0 & 127.0 & 254.0 \\
\hline
\end{tabular}

Source: Own calculation and estimation based on survey data.

Exp. Frq.: expected frequency Note: Pearson chi2(1) $=70.1793 \mathrm{Pr}=0.000$. 


\section{Household Health}

Women participation in VSL effect on women and their household health situation was measured by asking respondents (both participants and nonparticipants) perception towards their own and household members health status in the past 12 months (September 2016-September 2017).

The results of the chi-square test, as in Table $\mathbf{5}$ below, shows a Pearson's chi-square value of 70.193 with 1 degree of freedom and a significant level of 0.000 . The significance value is less than the given level of significance (0.05) leading to the rejection of the null hypothesis in favor of the alternative hypothesis. Thus, there is an association between improvement in household health and women participation in village saving and loan, and based on the results from Table $\mathbf{5}$, it can be concluded that women participation in VSL has a positive effect in improving the health status of women and their households as compared with non-participants.

To examine the effects of women participation in VSL in household health, participants in FGD were asked to reflect their views concerning the health situation of their own and their household members by comparing the before and after VSLA. Some of the participants in the FGD has explained their views towards VSL effects on household health as follows;

"The VSLA is really supporting us in various ways. Using the loan I took from the association, I am currently working in income generating activities and earn income. Before I join this association, I was not earning income and often wait for the hands of my husband, which was not enough for living, and when family members got sick, we were unable to pay for treatment and drug cost, enforcing us to apply to 'Kebele' for free health cards, to get free treatments and drugs from health centers. However, these things are improved after joining VSL and no longer apply for free treatments. Besides, we afford variety and healthy foods, keeps hygiene contributing a lot to prevent diseases. (FGD, 2017)

\section{Children's Education}

Like the preceding sections, the effect of women participation in VSL was measured by taking women perception towards their children education status. As the test variable, perception about children education is categorized as 1: improved, and 0: otherwise (including 'stayed the same', 'worsened', and 'I don't know'), and the group variable are both nominal, chi-square test is applied.

The results of the Chi-square test as shown in Table 6, The test shows Pearson chi-square value of 40.6505 with 1 degree of freedom and a significant value of 0.000 . As the significant level $(0.000)$ is less than the level of significance (0.05), the observed difference between participants and non-participants with regards to perception towards their children education is statistically significant. It can be said that there is association between women participation in VSL and improvement in children's education. Thus, it can be concluded that women participating in VSL have a favorable effect on children's education in relative to non-participants. This finding conforms with study by Brannen, C., $(2010,87)$, that found households participating in VSLA spend significantly more on education than non-participants and the difference in spending is statistically significant at $10 \%$ level of significance, implying participation in the VSLA

Table 6: Chi-Square Test - Respondents' Perception Towards their Children Education

\begin{tabular}{|c|c|c|c|}
\hline \multirow{2}{*}{ Perception on household diet } & \multicolumn{2}{|c|}{ VSL status } & Non-participants \\
\cline { 2 - 4 } & Participants & 10 & 75 \\
\hline \hline \multirow{2}{*}{ Improved } & 65 & 31.3 & 75.0 \\
\cline { 2 - 4 } Otherwise (stayed same, I don't know) & 43.8 (Exp. Frq.) & 40 & 117 \\
\cline { 2 - 4 } & 47 & 88.8 & 80 \\
\hline \multirow{2}{*}{ Total } & 68.3 & 80.0 & 117.0 \\
\cline { 2 - 4 } & 112 & 112.0 & 192.0 \\
\hline
\end{tabular}

Source: Authors calculation and estimation based on survey data.

Exp. Frq.: expected frequency; Note: Pearson chi2(1) $=40.6505 \mathrm{Pr}=0.000$ 
program increasing educational attainment and/or improves the quality of education received.

A participant in focus group discussion has shared this concerning her views towards participation in VSL and her children's education;

"Before, I was not able to send my children to school. This was mainly because I was not able to buy scholastic materials, uniforms and pay registration and semester fees. In some occasions, the city Women and Children Affairs Department together with some nongovernmental organizations such as Mary Joy have provided my children scholastic materials, and uniforms. Through these supports, some of my children went to school for some time, but I was not able to retain them for long. However, currently all my children are attending schools. Thanks to VSLA, I took loan started small business and make my own earning out of which I am paying for my children school materials, pay school registration and semester fees." (FGD, 2017)
Another participant in the focus group discussion shared her experience about her children academic results comparing before and after her participation in VSL.

"...Earlier, even if my children were going to school their results were not satisfactory. This poor result was mainly because they were attending school half day and most of them work afterwards to earn some for the household. They often got tired on evenings and did not study their lessons. However, now things are improved. As I am earning income from my small business; I am not letting my children to work after school. They have time to play and study as well. Recently, I have seen that their academic results are improving and hope this will continue in future too." (FGD, 2017)

Most of the views reflected by participants in the focus group discussion shows that women participation in VSL is positively contributing towards increasing the children enrollment in schools and improving their children academic results.

Table 7: Chi-Square Test- Respondents Participation in Household Decision Making

\begin{tabular}{|c|c|c|c|}
\hline \multirow{2}{*}{ Decision in household } & \multicolumn{2}{|c|}{ VSL status } & \multirow{2}{*}{ Total } \\
\hline & Non-Participants & Participants & \\
\hline \multirow{3}{*}{ Women only } & 43 & 49 & 92 \\
\hline & 46.74 & 53.26 & 100.00 \\
\hline & 33.86 & 38.58 & 36.22 \\
\hline \multirow{3}{*}{ Husband/spouse only } & 13 & 2 & 15 \\
\hline & 86.67 & 13.33 & 100.00 \\
\hline & 10.24 & 1.57 & 5.91 \\
\hline \multirow{3}{*}{ Women and husband jointly } & 38 & 73 & 111 \\
\hline & 34.23 & 65.77 & 100.00 \\
\hline & 29.92 & 57.48 & 43.70 \\
\hline \multirow{3}{*}{ Someone else } & 11 & 1 & 12 \\
\hline & 91.67 & 8.33 & 100.00 \\
\hline & 8.66 & 0.79 & 4.72 \\
\hline \multirow{3}{*}{ Respondent \& someone } & 22 & 2 & 24 \\
\hline & 91.67 & 8.33 & 100.00 \\
\hline & 17.32 & 1.57 & 9.45 \\
\hline \multirow{2}{*}{ Total } & 127 & 127 & 254 \\
\hline & 50.00 & 50.00 & 100.00 \\
\hline
\end{tabular}

Source: Authors calculation and estimation based on survey data. Note: Pearson chi2(4) $=44.4940 \mathrm{Pr}=0.000$. 


\section{Women's Household Decision Making}

The study tried to observe women's participation in VSL and its effect in household decision making. Women participants in VSL earning own income from their income generating activities are expected to make contributions to the total household income, which in turn help them to have say on household affairs.

The chi-square test result shows that Pearson chisquare value of 44.4940 at 4 degrees of freedom and significant value of 0.000 . The significant value is less than the level of significance (0.05) used in the study. Thus, we reject the null hypothesis in favor of the alternative. Hence, there is an association between women participation in VSL and household decision making. And women participation is positively impacting women to take active part in household decision makings.

In the focus group discussion, participants were asked what role they play in the decision-making process of their household, and if there is any change after joining VSL. Most of the participants seem to agree that most decisions are made in consultation with their spouses and women participation in VSL has increased their role in decision makings as well. In this regard, a participant has this to share;

"As far as I know, decisions in household are made depending on the urgency, importance and situation. There are decisions which are either made by me or my spouse, while others are made jointly and sometimes involving other concerned household members as well. Major decisions in the household particularly decisions concerning household income allocation and expenditure are made jointly with my spouse. Especially after I joined the VSLA and started to make money, most decisions are made after thoroughly discussion and mutual consensus with my spouse." (FGD, 2017)

\section{Women's Participation in Community-Based Organizations}

The chi-square test shows a Pearson's chi-square value of 1.5761 with 1 degrees of freedom and a significant value of 0.209 . As the significant value $(0.209)$ is higher than the level of significance (0.05), the null hypothesis is accepted. Thus, there is no association between participation in community-based organizations and women participation in VSL, and there is no statistically significant difference between participants and non-participants. It can be concluded that the effect of VSL participation has no effect on women participation in community-based organizations and activities.

In addition, participants reflected about their participation in community activities by comparing the before and after situation. A participant has this to say with respect to her participation in community activities after joining VSL;

"VSLA association made a significant role in helping women to express their views and share social, economic, cultural aspects. For instance, throughout our weekly meetings, beside saving and discussions about loan, we usually have some agendas to discuss including security issues in our village, crime prevention, health, sanitation and hygiene, children education and others. Some of the agendas discussed in our association are passed to local administrative and

Table 8: Chi-Square Test- Respondents Participation in Community-Based Organization

\begin{tabular}{|c|c|c|c|}
\hline \multirow{2}{*}{ Participation in CBO } & \multicolumn{2}{|c|}{ VSL status } & \multirow{2}{*}{ Total } \\
\cline { 2 - 4 } & Non-Participants & Participants & 237 \\
\hline \hline \multirow{2}{*}{ Yes } & 116 & 121 & 237.0 \\
\cline { 2 - 4 } & 118.5 & 118.5 & 17 \\
\hline \multirow{2}{*}{ No } & 11 & 6 & 17.0 \\
\cline { 2 - 4 } & 8.5 & 8.5 & 254 \\
\hline & 127 & 127 & 254.0 \\
\hline
\end{tabular}

Source: Authors calculation and estimation based on survey data. Note: Pearson chi2(1) $=1.5761 \mathrm{Pr}=0.209$. 
community-based organizations like 'Eder'

to get a higher emphasis and put the plans

into actions." (FGD, 2017)

In the focus group discussion, participants were asked if they have ever faced challenges, and limitations in their VSL participation and income generating activities. Most of the focus group discussion participants expressed that; despite their tireless efforts to change their own and family life, they are encountering some challenges. Among others, one of the participants in the focus group discussion has shared the challenges as follows, and most are shared by almost all participants;

"Most of us are working hard to change our life through VSLA. Despite our success in our engagement in income generation and raising income for our household, the support from government is loose. Local government is not providing the necessary support for us. We have not received any formal training concerning business, saving and book keeping. In addition to this, most of us working in 'Kochi', local market nearby our village, do not have permanent working place. And no tangible efforts have been done from government side to support us in this regard." (FGD, 2017)

\section{CONCLUSION AND RECOMMENDATIONS}

The study examined empirically the impact of village saving and loan associations in reducing household poverty among participating members in Hawassa city, Ethiopia. Using data from questionnaires and focus group discussions and applying propensity score matching (PSM) and comparative analysis through hypothesis testing. The findings from this study leads to the conclusion that women participation in village savings and loan association has a positive impact on key household poverty indicators such as average household monthly income; household diet, health, children's education, and women's decision makings in the household. The study also identified that there no significant association in relation to women participation in community. Based on the findings of this study, the following recommendations are suggested.

Firstly, building the competence of front line workers and improving the working environments are vital for the successful implementation of the VSLA. The study clearly identified that the need for capacity building, awareness creation of VSLA and creating ways to attract more community members in the processes of implementation is crucial. Hence, it is recommended that regular, timely and need based capacity building workshops for VSLA participants be provided and a sound working environment which attracts more frontline players be created. This facilitates the link between village saving and loan association participants with formal microfinance institutions or credit unions.

Secondly, since VSLAs depend on members' limited savings capacity to provide loan, loan demand of VSLA members can outpace supply, it is imperative for government to link the VSLA participants with microfinance institutions. This linkage will have a double fold effect. On one hand, participants will be able to access microloan to expand their small businesses and make a giant step out of poverty. On the other hand, the participant, in addition to the VSLA, will get an extra convenient spot to save more money in small amounts in microfinance institution. In this regard, it is recommended that a cohesive effort should also be placed by all relevant role players and most importantly regular monitoring and follow ups should be conducted by either the city or concerned government body.

\section{REFERENCES}

Allen, H., \& Hobane, P. 2004. Impact Evaluation of Kupfumalshungu. Arusha, Tanzania. CARE International.

Anyango, E. 2005. CARE Malawi Central Region Livelihood Security Project Impact Assessment Report on Village Savings and Loans Component (VS\&L). CARE International.

Arpino, B. \& Aassve A. 2005. Estimating the Causal effect of fertility on economic wellbeing: Data Requirements, identifying assumptions and estimation methods. Empirical Economics 44: $\mathrm{Pp}$ 355-85. https://doi.org/10.1007/s00181-010-0356-9

Bamlaku A.,2006. Micro financing and Poverty Reduction in Ethiopia. University of Giessen.

Barnes C. 2001.Microfinance Program Clients and Impact: An Assessment of Zambuko Trust, Zimbabwe. Assessing the Impact of Microenterprise Services (AIMS) Management Systems International

Becker, S. O., and A. Ichino 2002: Estimation of Average Treatment Effects Based on Propensity Scores. The Stata Journal, 2(4), Pp 358-377. https://doi.org/10.1177/1536867X0200200403

Bekele, E. \& Jacobs, P., 2008. Women entrepreneurship in micro, small and medium enterprises: The case of Ethiopia. Journal of International Women's Studies, 10(2): Pp 3.

Bekele, E. \& Worku, Z., 2008. Factors that affect the long-term survival of micro, small and medium enterprises in Ethiopia. South African Journal of Economics, Vol. 76(3): 548-568. https://doi.org/10.1111/j.1813-6982.2008.00207.x 
Brannen, C., 2010. An Impact Study of the Village Savings and Loan Association (VSLA) Program in Zanzibar, Tanzania. Unpublished Bachelor of Arts thesis. Wesleyan University.

Bryson, A. 2002: "The Union Membership Wage Premium: An Analysis Using Propensity Score Matching," Discussion Paper No. 530, Centre for Economic Performance, London.

Caliendo M \& Kopeinig S, 2008. Some practical guidance for the implementation of propensity score matching. Journal of Economic Surveys 22(1): Pp 31-72. https://doi.org/10.1111/j.1467-6419.2007.00527.x

Dercon, S., Gilligan, D., Hoddinott, J., and Woldehanna, T. 2009. The Impact of Agricultural Extension and Roads on Poverty and Consumption Growth in Fifteen Ethiopian Villages. American Journal of Agricultural Economics 91, 4. https://doi.org/10.1111/j.1467-8276.2009.01325.x

Dillion A. 2011. Do Differences in the Scale of Irrigation Projects Generate Different Impacts on Poverty and Production? Journal of Agricultural Economics, 62(2): Pp 474-492. https://doi.org/10.1111/j.1477-9552.2010.00276.x

Dinbabo, MF., 2014. Contractual Relationships between Indigenous Community Based Organizations (CBOs) and the Community: Empirical Evidence from Ethiopia. Journal of Social Sciences, 38(3), Pp.231-240. https://doi.org/10.1080/09718923.2014.11893253

Dinbabo, MF., 2013. Child rights in Sub-Saharan Africa: a call for a right-based global research agenda. Journal of Social Work. 48(1): Pp $271-293$

Dinbabo, MF., 2012.Community Based Organizations (CBOs) and Local Development: A case study in Ethiopia. Germany: academic publications.

Dinbabo, MF., 2011. Social Welfare Policies and Child Poverty in South Africa: A Microsimulation model on the Child Support Grant. Unpublished PhD Thesis. Cape Town: University of the Western Cape.

Dinbabo, MF., 2005. Indigenous Community Based Organizations (CBOs), the community and local development: A case study of Gubre in Ethiopia. Unpublished Master's Thesis. Germany: Institute of Development Research and Development Policy, Ruhr University.

Dunn, E. \& Arbunkle, G., 2001. The Impacts of Microcredit: A Case Study from Peru. USAID - AIMS Paper. Washington, D.C.

Edengenet Z.T., 2016. Women economic empowerment trough village saving and loan association: the case of Loka Aabaya district, Sidama zone of SNNPR. Unpublished Masters Thesis. Indira Gandhi National Open University. India.

Fekadu N.D. 2013. Impact of Integrated Village Saving and Loan Program: Empirical Evidences from the Northern Part of Ethiopia. Institute of Development Policy and Management, Antwerp, Belgium.

Fredrik G. 2013. The Impact of Microcredit on women's Empowerment. Unpublished Master's Thesis. Lund University. Sweden.

Gertler P.J., Martinez S., Premand P., Laura B. R.,Vermeersch C. M. J. 2011. Impact Evaluation in Practice. The World Bank. BN 978-0-8213-8541-8 -- ISBN 978-0-8213-8593-7. https://siteresources.worldbank.org/EXTHDOFFICE/Resourc es/5485726-

1295455628620/Impact_Evaluation_in_Practice.pdf

Gujarati D.N .2004. Basic Econometrics. Fourth Edition. McGraw Hill Book Co, New York

Haughton, J. and Khandker S. R. 2009. Handbook on Poverty and Inequality. World Bank Publications.

Hongo A. L. 2013. Influence of Savings and Loans Associations in Empowering Women towards Household Food Security in Bondo District, Kenya. Unpublished Master's Thesis. University of Nairobi, Kenya.
Hossaena, 2013. Women empowerment through microfinance: the case of village saving and loan association in KurfaChelle district, East Hararghe Zone, Oromia Regional state, Ethiopia. Unpublished Master's Thesis. Haramaya University.Ethiopia.

Hugh, A., 2002. CARE International's Village Saving and Loan Associations. Microfinance for the Rural Poor that Works.

Kabeer, N. 1997. Micro-credit and its Impact on Poverty, Wellbeing and gender equity: Some evidence from Bangladesh and India. Presentation at the International Workshop on Gender, Poverty and well-being: Indicators and Strategies' organized by UNRISD, UNDP \& CDS at Kerala.

Khandker. 2003. Microfinance and Poverty: Evidence using panel data from Bangladesh. https://doi.org/10.1596/1813-9450-2945

Khandker, S.R. 2005. Microfinance and Poverty: Evidence Using Panel Data from Bangladesh. The World Bank Economic Review. 19: Pp 263-286. https://doi.org/10.1093/wber/lhi008

Khandker, S. R., Koolwal, G. B., \& Samad, H. A. 2010. Handbook on impact evaluation: Quantitative methods and practices. Washington, DC: The World Bank. https://doi.org/10.1596/978-0-8213-8028-4

Kothari, C. R. 2004. Research Methodology: Methods and Techniques. New Delhi: New Age. International Private Limited Publisher.

Leuven, E. \& Sianesi, B. 2003. PSMATCH2: Stata module to perform full Mahalanobis and propensity score matching, common support graphing, and covariate imbalance testing".

Mochoge, N. W. 2016. Effects of Village Savings and Loans on Rural Women Livelihood Outcomes Among Women Groups in Kisii County. Unpublished Thesis, School of Business.

Morduch, J. 1998. Does microfinance really help the poor? New evidence from flagship programs in Bangladesh. $\mathrm{http}: / / \mathrm{www}$.microfinancegateway.org/gm/document.

Mutesasira, L. K. \& Mule. N. R. 2003. Understanding the West Nile SLAs and Charting a path for the Future.

Pitt, Mark M., and Shahidur R. Khandker. 1998. "The Impact of Group-Based Credit Programs on Poor Households in Bangladesh: Does the Gender of Participants Matter?" Journal of Political Economy 106(5): Pp 958-96. https://doi.org/10.1086/250037

Rosenbaum, P., and D. Rubin .1983. "The Central Role of the Propensity Score in Observational Studies for Causal Effects," Biometrika, 70, Pp 41-50. https://doi.org/10.2307/2335942

Sherin G.A. 2012. The effectiveness of microcredit programmes on alleviating poverty and empowering women in Cairo, Egypt. Unpublished Master's Thesis. Norway.University of Agder.

Terry, W.E., 2006. The Impact of Micro-Finance on Women MicroEntrepreneurs in Temeke District, Dar-es-Salaam, Tanzania. Masters Unpublished Thesis. The Faculty of the Center for International Studies of Ohio University.

Thuysbaert B. 2012. Impact of Village Savings and loan Associations. Findings from Ghana, Malawi, and Uganda. https://www.povertyaction.org/sites/default/files/day_3_s2_thuysbaert.pdf.

Todd H., 2000. Poverty Reduced Through Microfinance: The Impact of ASHI in the Philippines. An ASHI-CASHPOR- PHILNET Impact Assessment Supported by the AIMS Project 19 March - 8 April. Washington, D.C.: AIMS

Wosene A., 2014. Poor women and their Social Capital: An Exploratory Study of the Village Saving and Loan Groups' Contribution to Women's Empowerment in Ethiopia, West Harergie. Unpublished Master's Thesis. Indira Gandhi National Open University. New Delhi. India. 
Wordofa M.G. \& Sassi M. 2017. Impact of Farmers' Training Centres on Household Income: Evidence from Propensity Score Matching in Eastern Ethiopia. Social Science article 1-12. https://doi.org/10.3390/socsci7010004
Yamane, T., 1967. Statistics, an Introductory Analysis, 2nd Ed., New York: Harper and Row.

Yunus, M., 1999. Banker to the poor: Micro-lending and the battle against world poverty. Public Affairs.

Received on 30-04-2019

Accepted on 01-06-2019

Published on 07-08-2019

DOI: https://doi.org/10.6000/1929-7092.2019.08.49

(C) 2019 Beyene and Dinbabo; Licensee Lifescience Global.

This is an open access article licensed under the terms of the Creative Commons Attribution Non-Commercial License (http://creativecommons.org/licenses/by-nc/3.0/) which permits unrestricted, non-commercial use, distribution and reproduction in any medium, provided the work is properly cited. 